\title{
Leitura e interpretação de enunciados de problemas escolares de matemática por alunos do ensino fundamental regular e educação de jovens e adultos (EJA)
}

\section{Reading and interpretation of school mathematics problems by students of regular elementary school and from the youth and adults education system}

\author{
Regina Maria Pavanello ${ }^{1}$ \\ Silvia Ednaira Lopes ${ }^{2}$ \\ Nelma Sgarbosa Roman de Araujo²
}

\begin{abstract}
RESUMO
Neste trabalho analisamos a compreensão leitora de alunos do ensino fundamental (na estrutura regular e no sistema de Educação de Jovens e Adultos - EJA) de enunciados de problemas escolares de Matemática necessária à resolução destes. Os dados para a análise foram coletados por meio de entrevistas realizadas com vinte alunos do ensino fundamental regular (dez alunos da 5. ${ }^{a}$ série e dez da $8 .^{a}$ ) e dez do EJA (cinco concluintes da Fase I e cinco concluintes da Fase II do ensino fundamental). Nas entrevistas, pautadas no método clínico-crítico de Jean Piaget, foram apresentados aos participantes quatro problemas adaptados de duas das coleções didáticas mais utilizadas pelos professores da região em sala de aula. A análise dos dados foi fundamentada na noção bakthiniana de gênero discursivo e em autores que focalizam aspectos cognitivos da leitura e interpretação de textos
\end{abstract}

1 Doutora em Educação pela Universidade Estadual de Campinas (UNICAMP), Brasil. Docente do Programa de Pós-Graduação em Educação para a Ciência e a Matemática da Universidade Estadual de Maringá, Paraná, Brasil.

2 Mestres em Educação para a Ciência e a Matemática pelo Programa de Pós-Graduação para a Ciência e a Matemática da Universidade Estadual de Maringá (UEM), Paraná, Brasil. 
como Solé e Kleiman, a comunicação e a linguagem na prática educativa em matemática como Gómez-Granell, e a resolução de problemas como Bacquet e Medeiros. Os resultados mostraram que os participantes apresentavam falhas em sua compreensão leitora conforme os pontos de vista linguístico e matemático e pouca familiaridade com o gênero discursivo "enunciado de problemas matemáticos"; também não tinham noção precisa do significado de resolver um problema e apresentavam dificuldade em reter e manter o controle adequado das informações essenciais dos enunciados.

Palavras-chave: educação matemática; leitura e interpretação de problemas escolares de matemática; ensino fundamental; educação de jovens e adultos.

\begin{abstract}
This paper examines the reading comprehension of Elementary School students (in the regular structure and in the Youth and Adults System- EJA) concerning statements of school mathematics problems which are needed to their resolution. Data were collected by interviewing twenty elementary school students in regular structure (ten 5 th graders and ten 8 th graders) and 10 students attending the EJA (five Stage I graduates and five Stage II graduates). Based on Piaget's critical-clinical method, the interviews presented to each subject had four problems adapted from two of the didactic collections more frequently used by local teachers in their classrooms. Data analysis was based on the Bakthinian notion of discursive genre and on authors that focus on cognitive aspects of reading and interpretation of texts as Solé and Kleiman; communication and language in educational practice in mathematics as Gómez-Granell, and on problem solving as Bacquet, and Medeiros. Results showed that subjects had failures in their reading comprehension in terms of linguistics and mathematics, and were unfamiliar with the "statement of mathematical problems" discursive genre; they also had no precise idea of what could mean solving a problem and had difficulty on retaining and maintaining adequate control of essential information present at the statements. Keywords: mathematics education; reading and interpretation of school mathematics problems; elementary education; youth and adults education.
\end{abstract}

\title{
$O$ contexto da pesquisa
}

Este texto tem o objetivo de analisar a compreensão leitora de alunos do ensino fundamental de enunciados de problemas escolares de matemática. Os 
dados aqui analisados provêm de duas pesquisas, uma realizada pela segunda autora com alunos desse nível da escolarização na estrutura regular e, outra, realizada pela terceira autora, com estudantes do sistema de Educação de Jovens e Adultos (EJA).

Nosso interesse por esta questão tem origem em nossa atuação como professoras de Matemática na escola básica e em cursos de formação continuada de docentes. No ambiente escolar ou durante os referidos cursos temos ouvido relatos recorrentes sobre as dificuldades dos alunos do ensino fundamental em atividades de resolução de problemas. Comentam os professores que muitos alunos, dizendo-se incapazes de resolver os que lhes são propostos, recusam-se a pensar sobre como poderiam iniciar sua resolução e insistem para o docente indicar como devem proceder.

Por certo, poder-se-ia pensar que o principal obstáculo encontrado para o bom desempenho dos estudantes seria o de estes não dominarem os procedimentos de cálculo necessários (algoritmos, equações). Mas isto, a nosso ver, não explicaria por completo o sentimento de impotência experimentado por eles nesse tipo de atividade escolar. Essa é uma das razões que nos levaram a conjecturar se as dificuldades dos alunos da escola básica na resolução dos problemas que lhes são propostos em sala de aula não decorreriam de eles não compreenderem com clareza o que os professores e os livros didáticos querem lhes comunicar.

Esta não é uma suposição sem fundamento, uma vez que, cada vez mais, estudiosos como Pedro (1992) conscientizam-se de que, se a linguagem é um dado essencial de toda prática educativa, sua compreensão não é imediata, cristalina. Estudos realizados no campo da linguística (como os de HENRY, 1992; ou FERREIRA, 2000) indicam que, na comunicação em geral e no ensino das diferentes disciplinas em especial, um dos principais problemas que os alunos têm de enfrentar pode estar ligado à estrutura da própria língua, suas contradições, deslocamentos, equívocos e ambiguidades.

Além disso, a compreensão dos alunos sobre as informações comunicadas pelo professor ou pelo livro didático depende não só do conhecimento que aqueles trazem para o ambiente escolar (seu repertório linguístico, seu conhecimento sobre o mundo), mas também do assunto apresentado, como isso é feito. Depende também das oportunidades de negociação que o professor lhes dá em relação ao significado e à importância daquilo que devem aprender.

Por outro lado, na sala de aula de matemática uma dificuldade a mais se interpõe: o uso, na comunicação nesse campo do conhecimento, de objetos da língua materna com um sentido diferente (em geral mais restrito, mais particular) daquele empregado em outros ambientes (um quarto, em matemática, não significa um cômodo da casa), fato esse do qual nem sempre os professores têm consciência. 
Uma fala de Bruner parece dar pistas para compreendermos melhor as dificuldades dos alunos em relação à matemática:

As pessoas em geral e as crianças em particular têm um pensamento do tipo narrativo, orientado para a construção de fenômenos concretos, pessoais e intencionais, enquanto o pensamento matemático tem caráter paradigmático, que suprime intenções e motivações e baseia-se em representações abstratas e muito gerais (BRUNER, apud GÓMEZGRANELL, 1998, p. 34).

Disso decorre, conforme explicitado por D'Antonio (2006), que muitos alunos, ao chegarem à sala de aula, acostumados aos sentidos que circulam na linguagem cotidiana, apresentam dificuldades para relacioná-los aos conceitos e ideias da matemática tratados na escola. Ou seja, no aprendizado da matemática, o aluno, além de se deparar com os problemas inerentes à linguagem e ao ato da comunicação, deve lidar também com uma linguagem mais formal, a da matemática, restrita em certos aspectos, mas com conotação ampla em muitos outros (BELLINI; RUIZ, 1998).

Assim sendo, na comunicação no âmbito da educação matemática é necessária a consciência das falhas e dos limites da língua e, em decorrência, da linguagem matemática, bem como da descontinuidade existente entre a cultura social do aluno e a da escola, entre seus conhecimentos e aqueles com os quais se defronta em sala de aula.

Isso posto, nos propusemos a seguinte questão de pesquisa: até que ponto a linguagem comum e a linguagem matemática interferem na leitura e na compreensão pelos alunos do ensino fundamental dos problemas que lhes são propostos em sala de aula e nos livros didáticos?

\section{Sobre a leitura e a compreensão de textos}

A proposição desta questão para nortear nossa pesquisa nos levou a dialogar com autores que tratam da leitura e da compreensão de textos, como Solé (1998) e Kleiman (2004) entre outros.

Conforme Solé (1998), a leitura é uma atividade dinâmica que permite ao leitor relacionar-se com o mundo, compreender a realidade e o ambiente cultural 
da sociedade em que está inserido. Como todas as situações de comunicação, é uma atividade de natureza simbólica, em que os signos interagem com os componentes culturais envolvidos em um determinado texto para permitir sua apreensão e compreensão pelo leitor. Para a autora, a leitura não se constitui apenas na decodificação dos signos, mas trata-se de um processo de interação entre o leitor e o texto, com ele estabelecendo algum tipo de diálogo. Configurase, portanto, como um processo no qual o pensamento e a linguagem estão envolvidos em trocas contínuas.

Smith (1989) caminha na mesma direção ao salientar que a compreensão, uma habilidade essencial no processo de aprendizagem, só se concretiza, quando o leitor for capaz de contemplar o que o texto traz por escrito (os elementos visuais, para cuja compreensão deve recorrer ao seu conhecimento linguístico e textual) e o que não está escrito (elementos não visuais, o seu conhecimento de mundo).

Por outro lado, os autores ressaltam também que, para compreender um texto, o leitor precisa ter em vista os objetivos que levaram esse texto a ser escrito e ancorá-lo em ideias e experiências prévias. E que cabe à escola - e a todos os professores - a tarefa de apresentar aos estudantes diferentes tipos de textos e discutir com eles os objetivos a partir dos quais foram escritos, as ideias que são neles abordadas, de modo a proporcionar o desenvolvimento de estratégias de leitura para gêneros textuais próprios às diferentes disciplinas escolares.

\section{O enunciado dos problemas como um gênero discursivo}

Tal discussão nos leva a considerar Bakhtin (1992), que ressalta serem gerados, para cada esfera da atividade humana, ou para cada esfera de comunicação verbal (oral ou escrita), tipos de enunciados relativamente estáveis no tocante ao tema, à composição, ao estilo. A esses tipos de enunciado que atendem a um propósito comunicativo Bakhtin denomina de gêneros discursivos.

$\mathrm{O}$ autor nos alerta sobre as dificuldades de compreensão de textos dizendo que

Muitas pessoas que dominam bem a língua se sentem, entretanto, totalmente desamparadas em algumas esferas de comunicação precisamente porque não dominam os gêneros criados por essas esferas. Não raro, uma pessoa que domina perfeitamente o discurso de diferentes esferas da comunicação 
cultural, que sabe dar uma conferência, levar a termo uma discussão científica, que se expressa excelentemente em relação a questões públicas, fica, não obstante, calada ou participa de maneira muito inadequada numa conversa trivial de bar. Nesse caso, não se trata da pobreza de vocabulário nem de um estilo abstrato; simplesmente trata-se de uma inabilidade para dominar o gênero da conversação mundana, que provêm da ausência de noções sobre a totalidade do enunciado, que ajudem a planejar seu discurso e determinar formas composicionais e estilísticas (gêneros) rápida e fluentemente; uma pessoa assim não sabe intervir a tempo, não sabe começar e terminar corretamente (apesar desses gêneros serem muito simples) (BAKHTIN, 1992, apud BRÄKLING, 2006, p. 1).

Concordamos, então, com Bräkling (2006, p. 1), que é dever da escola ensinar a seus alunos as características dos diferentes gêneros discursivos, porque eles "não são aprendidos espontaneamente nas situações do cotidiano". E, como esses textos diferem de disciplina para disciplina, os professores de cada uma delas devem assumir a tarefa de ensinar a seus alunos as características daqueles utilizados em suas aulas.

No trabalho escolar com a matemática, um dos tipos de texto utilizado é o do enunciado de problemas escolares, que pode ser considerado como um gênero discursivo a ser dominado pelos alunos. Sua interpretação vai além, como acreditam muitos professores, da pouca competência que os alunos possam ter ao fazer sua leitura na língua materna, porque nesses textos se combinam duas linguagens diferentes, as palavras e os símbolos matemáticos, linguagens estas que apresentam certas especificidades e que, portanto, demandam estratégias específicas de leitura.

Os entraves à resolução de problemas estariam, pois, também ligados à dificuldade dos alunos em decodificarem os termos matemáticos que aparecem nos enunciados e que, muitas vezes, têm um sentido próprio na matemática diferente daquele com que são usados no cotidiano.

\section{A pesquisa}

A literatura analisada nos levou a propor a seguinte formulação para o objetivo geral de nossa pesquisa: investigar o que facilita ou dificulta a interpretação dos enunciados e a resolução de problemas matemáticos escolares por alunos do Ensino Fundamental cursando a 5. ${ }^{\mathrm{a}}$ e a 8 . $^{\mathrm{a}}$ séries na modalidade 
regular (LOPES, 2007) e por aqueles cursando o equivalente a elas na Educação de Jovens e Adultos - EJA (ARAÚJO, 2007).

Para alcançar esse objetivo, nos propusemos a responder as seguintes indagações:

- Alunos de séries mais adiantadas, que têm um maior repertório vocabular e matemático, apresentam menos dificuldade em resolver os problemas matemáticos propostos pela escola?

- Alunos da Educação de Jovens e Adultos (EJA) têm as mesmas dificuldades que os do ensino regular?

A opção por realizar a investigação com dois grupos de alunos em cada modalidade de ensino teve por objetivo analisar se um tempo maior de escolarização, durante a qual foram familiarizados com outros conceitos e ideias da matemática, possibilitava aos estudantes uma melhor compreensão dos enunciados dos problemas e a mobilização de outros procedimentos para sua resolução. A escolha de alunos das duas modalidades do Ensino Fundamental teve como objetivo verificar se as dificuldades eram as mesmas ou haveria dificuldades específicas.

Participaram da pesquisa estudantes provenientes de duas escolas públicas de duas cidades da região noroeste do Paraná. Deles, 20 eram alunos do ensino fundamental regular, divididos em dois grupos: GI, constituído por 10 alunos da 5. ${ }^{\text {a }}$ série, e GII, por 10 da 8. ${ }^{a}$ série (LOPES, 2007).

Os alunos do programa de EJA participantes da pesquisa foram 10, dos quais 5 eram concluintes da Fase I (GI), e 5 concluintes da Fase II (GII) do ensino fundamental (ARAÚJO, 2007).

Os três participantes mais novos de EJA do Grupo I (A1, A3 e A5, com 26, 28 e 35 anos respectivamente) estudaram no ensino regular até a 5. a (A1) e 7. ${ }^{\text {a }}$ série (A3 e A5) e voltaram a estudar 10 anos (A1 e A3) e 19 anos (A5) após terem abandonado a escola; os dois mais velhos (A4 e A2, de 56 e 62 anos respectivamente) cursaram o ensino regular até a 7. ${ }^{a}$ (A4) e a 3. ${ }^{a}$ série (A2) no ensino médio e voltaram a estudar 40 anos após terem abandonado a escola.

No Grupo II, o mais velho (B3, 46 anos) cursou até a 4. ${ }^{a}$ série do ensino regular e voltou a estudar no programa de EJA cerca de 30 anos após ter abandonado a escola; outros dois (B1, de 35anos, e B2, de 37 anos) cursaram até a 4. ${ }^{\mathrm{a}}$ (B2) e a 5. ${ }^{\mathrm{a}}$ série (B1) no ensino regular e voltaram a estudar após 20 anos aproximadamente; outra aluna (B5, 25 anos) cursou até a $8 .^{\mathrm{a}}$ série no ensino regular e voltou após 4 anos e, o mais novo (19 anos) cursou até a $6{ }^{a}{ }^{a}$ série no ensino regular, passando em seguida para o programa de EJA.

A coleta de dados para a pesquisa, a qual se caracteriza como sendo de natureza qualitativa, foi feita por meio de entrevistas semiestruturadas, realizadas individualmente com cada participante e baseadas no método clínico-clínico pia- 
getiano (DOMADHY-DAMI; BANKS-LEITE, 1987). Nas entrevistas lhes foram apresentados quatro problemas, selecionados e adaptados dos livros didáticos mais utilizados na região, que envolviam conteúdos habitualmente abordados nessa fase da escolarização e podiam ser resolvidos com a utilização de diferentes procedimentos.

Esses problemas foram apresentados, um a um, a cada participante, em duas sessões. Antes de resolver cada problema, o participante deveria fazer uma leitura silenciosa de seu enunciado e, depois, uma leitura em voz alta, a qual tinha por objetivo permitir ao pesquisador observar se essa leitura era ou não fluente. Em seguida, o participante deveria explicar, com suas palavras, o que entendeu do enunciado e indicar o que nele não entendeu, seja do posto de vista da linguagem comum ou da linguagem matemática. Seria, então, estabelecida a interação entre participante e pesquisador com o objetivo de o sujeito superar a dificuldade, se possível, e prosseguir na resolução do problema em análise.

As entrevistas, gravadas em fita cassete e posteriormente transcritas, bem como as anotações feitas pelas pesquisadoras durante sua realização, foram os objetos da nossa análise.

Os problemas utilizados nas entrevistas foram os seguintes:

1. A soma de três números inteiros consecutivos é 63. Quais são os três números?

2. Todos os dias José faz um percurso de $850 \mathrm{~m}$. Desse percurso, $45 \%$ estão asfaltados.

a) Quantos metros estão asfaltados?

b) Quantos por cento do percurso não estão asfaltados?

c) Quantos metros não estão asfaltados?

d) Quantos metros correspondem a 100\%?

3. O perímetro de um retângulo é $72 \mathrm{~m}$. Sabendo que o lado maior é o dobro do menor, encontre as medidas dos lados do retângulo.

4. Com $\mathrm{R} \$ 8,00$ posso comprar dois gibis e três pacotes de figurinhas e ainda sobram $R \$ 2,00$ de troco. O gibi custa $R \$ 1,00$ a mais que o pacote de figurinhas. Quanto custa cada gibi? E cada pacote de figurinhas?

Considerando os interesses de participantes na faixa etária dos alunos da EJA, modificamos o problema 4, apresentando-os para nossos participantes com a seguinte redação:

4. Com $\mathrm{R} \$ 80,00$ poso comprar duas camisa, três pacotes de meias e ainda sobram $\mathrm{R} \$ 10,00$. Cada camisa custa $\mathrm{R} \$ 20,00$ a mais do que o pacote de meias. Quanto custa cada camisa? E cada pacote de meias? 


\section{Análise e discussão dos resultados}

Os dados colhidos nas entrevistas nos levaram a concluir que as dificuldades dos estudantes do ensino regular e os da EJA, excetuadas as relacionadas à fluência na leitura, são bastante similares em relação à resolução de problemas matemáticos escolares.

A pouca fluência na leitura dos enunciados foi observada majoritariamente entre os alunos da $5 .^{\mathrm{a}}$ série (GI) do ensino fundamental regular e em apenas um dos da 8. ${ }^{a}$ série (GII). E embora ela não possa ser considerada como o principal empecilho para a resolução dos problemas, os alunos que não eram fluentes foram os que apresentaram maior dificuldade na sua leitura e interpretação. Kleiman (2004) nos explica porquê. Segundo a autora, para o aluno ter maior facilidade na leitura e interpretação de um texto, ele deve ser capaz de reconhecer instantaneamente as palavras. Aquele que "lê mais vagarosamente, sílaba por sílaba, terá dificuldades para lembrar o que estava no início da linha quando chegar ao fim" (KLEIMAN, 2004, p. 36). Pesquisas como a de D'Antonio (2006) oferecem indícios de que esta dificuldade na leitura dos enunciados pode estar ligada a não ser comum que se proponha aos alunos a leitura desses textos em sala de aula, a leitura e a interpretação dos problemas sendo feita, quando esta ocorre, exclusivamente pelos professores.

Os resultados de nossa pesquisa nos levaram a concluir, como Medeiros (2001), que a complexidade envolvida no processo da resolução de problemas extrapola a fluência na leitura, a utilização ou não de certas estratégias ou conhecimentos conceituais isolados, e exige uma atividade cognitiva que ligue diversos elementos. Entendemos, assim, que a compreensão dos enunciados dos problemas matemáticos escolares e a utilização de abordagens apropriadas para sua resolução dependem de vários fatores, dentre os quais abordaremos especificamente os relacionados à compreensão leitora e à familiaridade com o gênero discursivo "enunciado de problemas matemáticos" e, quanto aos alunos da EJA, à utilização ou não da matemática no cotidiano.

De acordo com Santorum (2005), a compreensão leitora engloba três níveis de conhecimentos prévios constituintes da bagagem do leitor: o linguístico, o textual e o conhecimento de mundo. Saber pronunciar corretamente as palavras, utilizar de forma apropriada as regras da língua, dominar um amplo vocabulário, são partes integrantes do conhecimento linguístico, enquanto o conhecimento de diferentes tipos de textos e formas de discurso compõe o textual.

$\mathrm{O}$ conhecimento de mundo, adquirido formal ou informalmente, diz respeito ao esquema que cada leitor organizou dentro de si e que é o responsável 
por suas expectativas sobre a ordem natural das coisas. No caso dos participantes de nossa pesquisa, podemos acrescentar a este último o conhecimento prévio da matemática, construído por eles no decurso de sua história pessoal, no cotidiano ou na escola. E a este estão relacionados os procedimentos e as estratégias necessários à resolução de problemas.

Outro aspecto da capacidade leitora essencial à leitura e interpretação de enunciados de problemas é a relativa à retenção e ao relacionamento das informações neles contidas, uma vez que a falta desse controle pode implicar na não obtenção do(s) resultado(s) esperado(s).

Os dados colhidos nas entrevistas mostram que, de forma geral, os participantes dos quatro grupos demonstraram lacunas na compreensão linguístico/ matemática de termos ou expressões presentes nos enunciados, impeditivas para a resolução dos problemas propostos.

Solé (1998) alerta que

\begin{abstract}
As lacunas na compreensão podem ser atribuídas ao fato de [o aluno] não conhecer alguns dos elementos mencionados, ou ao fato de o significado atribuído pelo leitor não ser coerente com a interpretação do texto. Também podem existir diversas interpretações possíveis para a palavra, frase ou para um fragmento, e então a dificuldade reside em ter que decidir qual a mais idônea. Quando os problemas situam-se em nível do texto em sua globalidade, as dificuldades mais comuns referem-se à impossibilidade de estabelecer o tema, de identificar o núcleo da mensagem que se pretende transmitir ou à incapacidade de entender por que sucedem determinados acontecimentos (SOLÉ, 1998, p. 128).
\end{abstract}

Em nossa pesquisa, as lacunas ocorreram devido a alguns dos participantes não conhecerem o significado de palavras ou expressões presentes nos enunciados, enquanto outros atribuíam a elas significados não adequados à situação.

A principal dificuldade para a resolução do quarto problema, por exemplo, foi a maioria dos estudantes dos quatro grupos não entender o significado da expressão "a mais do que" constante do enunciado. Isto ocorreu com os alunos do ensino regular (todos os da $5 .^{a}$ série e cinco dos da $8 .^{a}$ ) e os da EJA (oito deles, quatro de cada grupo).

Em relação ao primeiro problema, a dificuldade foi com o termo "consecutivos", notada na maioria dos sujeitos da EJA (quatro do GI e todos do GII) e nos do ensino regular (nove dos da $5 .^{a}$ série e quatro dos da $8 .^{a}$ ). Embora muitos fossem capazes de explicarem o significado do termo em situações do cotidiano como "tomar um remédio por três dias consecutivos" ou "ter frequentado o clube 
por duas semanas consecutivas", a situação se complicava quando se pedia a transposição desse significado para o contexto da matemática. Isso porque para a resolução do problema não bastava à compreensão da sequência, havendo a necessidade de compreender a propriedade envolvida: a diferença entre um número e seu antecessor ou sucessor deve ser um.

Outra dificuldade apresentada pelos participantes foi com o termo "perímetro" usado no terceiro problema. Apesar de ser este um conteúdo abordado já nas séries iniciais do ensino fundamental, somente dois dos alunos da 5. a série e quatro dos da 8 . $^{\mathrm{a}}$ série do ensino regular demonstraram não ter dificuldade com relação ao seu significado, não necessitando da intervenção da pesquisadora para compreendê-lo. Quanto aos alunos da EJA, todos apresentaram dificuldade não só para a compreensão desse termo, como também com a de "retângulo".

Assim como Kleiman (2004), consideramos ser o conhecimento linguístico um conhecimento prévio fundamental para a interpretação de textos. Assim sendo, as lacunas demonstradas por nossos sujeitos e/ou o fato de esse conhecimento não estar bem fundamentado impossibilitaram a compreensão dos enunciados dos problemas e, consequentemente, a possibilidade de sua resolução.

No entanto, essa compreensão não pode ser atribuída somente ao parco conhecimento da língua materna pelos alunos como apontam alguns autores (MACHADO, 2001), mas tem raízes também em seu conhecimento limitado desse gênero textual "enunciado de problemas matemáticos". Se assim não fosse, pessoas com bom domínio da língua não enfrentariam dificuldades na compreensão desses textos, o que temos visto não ocorrer.

A resolução de um problema exige do aluno a familiaridade com um gênero discursivo com características semelhantes às de uma narração de fatos, embora não podendo ser com ela confundido, porque seu objetivo é apresentar informações que tornem possível responder a uma questão. Como cada informação é essencial para se chegar a essa resposta, é necessário que o estudante as compreenda bem, não só do ponto de vista linguístico, como também do matemático. E observamos que houve participantes, mesmo entre aqueles cursando um nível mais elevado da escolarização, que mostraram não compreender o significado das operações fundamentais da aritmética para poder utilizá-las apropriadamente na resolução dos problemas apresentados.

No transcorrer da pesquisa verificamos ainda que nem todos os alunos dos quatro grupos tinham consciência do que significa resolver um problema matemático. Expostos à situação de ter que resolver um, alguns dos entrevistados realizavam uma operação qualquer utilizando os dados informados, sem analisar mais detidamente seu enunciado. ALE (5. ${ }^{\mathrm{a}}$ serie), por exemplo, efetuou a soma de 63 com 3 para resolver o primeiro problema, por levar em consideração apenas o termo "soma" nele presente. Outros, como JOI ( $8 .^{\text {a }}$ série), foram realizando 
todas as operações possíveis, aleatoriamente, com as quantidades presentes no segundo problema, demonstrando crer na necessidade de realizar uma operação qualquer, embora não sabendo qual.

Concordamos com Bacquet (2001), para quem o aluno deve, para resolver um problema, não somente compreender seu enunciado, mas o verdadeiro sentido da pergunta, para, só então, decidir qual a operação mais adequada à busca de uma resposta.

Outro aspecto observado durante as entrevistas foi o número significativo de sujeitos que mostraram dificuldade em reter e manter o controle adequado das informações essenciais dos enunciados, fato esse que ocorreu principalmente no caso dos problemas 3 e 4 . Alunos do ensino regular de ambos os grupos e do Grupo I da EJA, ao resolverem cada situação apresentada procuravam solucioná-la detendo-se em somente uma das informações ali contidas e não voltando ao texto do enunciado para verificar a existência de outras informações necessárias à obtenção da resposta correta. Do que se depreende que eles não tinham consciência de que a coordenação entre as informações era determinante para o sucesso de sua resolução.

Esse desconhecimento dos alunos sobre o que significa resolver um problema e como se deve proceder para encontrar sua solução nos reportou ao relato, no trabalho de D'Antonio (2006), sobre como são realizadas as atividades de resolução de problemas em sala de aula. Conforme a autora, é o professor que, em geral, faz a leitura do problema e se encarrega de sua resolução, a interpretação dos resultados consistindo, muitas vezes, somente em ligar um termo do enunciado a uma operação (ligando a palavra "pagar", por exemplo, à subtração). E falas de nossos sujeitos confirmam que as dificuldades dos alunos podem estar relacionadas a como essas atividades são abordadas. A esse respeito, nos reportamos a RO (GI, ensino regular) que, frente a um dos problemas, diz: "esta pergunta tá muito difícil, quando a professora dá um problema assim difícil, ela vai para a lousa e resolve logo para a gente".

Um trecho da entrevista de B1 também confirma não haver no EJA espaço para a discussão e a reflexão quanto à resolução de problemas nas aulas de matemática: "Na hora que ela [a professora] tá passano, você presta atenção, aí faz ali no quadro, mas não é uma coisa assim do dia a dia, que acontece assim, que você vai fazê num concurso, é muito diferente! Não tem aquelas coisas ali”".

Nossos resultados mostraram que a superioridade dos alunos das séries mais adiantadas relativa à resolução de problemas não foi tão significativa quanto esperávamos, nem no tocante ao repertório vocabular, nem ao matemático, pois apresentaram praticamente as mesmas dificuldades que os da $5 .{ }^{a}$ nesse quesito.

Um dado importante, a nosso ver, é o procedimento majoritariamente utilizado pelos estudantes dos diferentes grupos nessa resolução ter sido a tentativa 
aleatória. Somente alguns deles utilizaram algum parâmetro em suas tentativas, demonstrando com isso certa expectativa sobre o resultado ou alguma noção do algoritmo a utilizar. Além disso, verificamos que nenhum dos alunos dos grupos II (nível de 8. ${ }^{a}$ série), que já haviam estudado álgebra nos anos anteriores, utilizou esse conhecimento para resolver os problemas propostos. Não que eles necessariamente tivessem que a utilizar. Mas muitos deles, no entanto, quando indagados se haveria alguma outra forma de resolvê-los, invariavelmente diziam que, se havia, não se lembravam.

Acreditamos que esses sujeitos ainda não teriam consolidado a transição da representação natural para a linguagem algébrica, a qual, segundo vários estudos (KLÜSINER, 2000, p. 181), tem se mostrado como "um obstáculo cognitivo na aprendizagem da álgebra".

Ainda no tocante aos procedimentos utilizados na resolução dos problemas, em especial na do segundo deles, em que o conteúdo abordado era a porcentagem, observamos que alunos da EJA recorreram àqueles que utilizavam no cotidiano e/ou trabalho. No entanto, verificamos que, embora chegassem aos resultados das questões com facilidade, nem sempre tinham clareza sobre o porquê dos procedimentos utilizados. Alunos que conseguiram chegar ao resultado correto da primeira questão do problema citado, por exemplo, não conseguiam explicar esse procedimento do ponto de vista matemático. Do que se conclui que os conhecimentos prévios que apresentavam, provenientes da prática cotidiana, não haviam sido formalizados (fundamentados) pela escola de modo a lhes propiciar uma compreensão mais abrangente desses conhecimentos.

\section{Considerações finais}

A análise apresentada aqui, mais do que apontar as dificuldades dos alunos na resolução de problemas, nos remete a algumas considerações sobre o ensino e a aprendizagem de matemática.

Constatamos, com a realização da pesquisa, a existência de uma distância entre a leitura e a interpretação que os alunos conseguem fazer dos enunciados e a que gostaríamos que fizessem. E compreendemos, com Solé (1998), que a habilidade de ler e interpretar esses textos não se desenvolve espontaneamente, mas deve ser objeto de um trabalho específico do professor, no qual este, num primeiro momento, ofereça aos alunos um modelo de como isso deve ser feito. Ou seja, o professor deve explicitar o que faz quando lê e interpreta um enunciado, deve mostrar porque é necessário retornar a ele, não só para verificar se 
todas as informações importantes foram utilizadas, como também para avaliar se a resposta encontrada atende às condições do problema.

No entanto, a já citada fala de RO, aluna da 5. ${ }^{\mathrm{a}}$ série do ensino fundamental regular, juntamente com os relatos de D'Antonio (2006), indicam não ser feito na escola um trabalho específico de interpretação de seus enunciados com os alunos. Foi importante constatar que os estudantes da EJA fizeram questão de avaliaram como positiva sua participação na pesquisa porque tinham tido com ela a oportunidade talvez única de discutirem esse tipo de textos, de refletirem e aprenderem nas interações com a pesquisadora. E lamentaram o pouco tempo que têm durante o curso para que um trabalho como o realizado na pesquisa possa ser feito, permitindo um atendimento especial para suas dificuldades.

Um ponto de reflexão suscitado pelo trabalho que efetuamos é a existência de lacunas nos conhecimentos prévios dos alunos que, muitas vezes, passam despercebidas pelo professor em seu trabalho diário em classe.

Compreendemos ainda, com a realização da pesquisa, que um ponto a ser considerado no processo de ensinar/aprender matemática é o da comunicação em sala de aula dever ser utilizada como um instrumento mediante o qual professores e alunos orientem mutuamente sua atividade com o objetivo de partilharem seus significados matemáticos ou linguísticos. Deve essa comunicação constituir-se em uma prática que revele a possibilidade de diferentes interpretações para enunciados ou tarefas entre os sujeitos do ato educativo, tornando aceitáveis certas respostas que seriam avaliadas como erradas caso prevalecesse sempre a interpretação do professor - mesmo que esta nem sempre esteja correta. Em tal processo comunicativo, o significado matemático não é imposto, mas passa a ser objeto de negociação.

Somente uma prática em que o aluno possa manifestar seu pensamento, discutir sua interpretação de um texto, expor sua compreensão de uma situação qualquer e realmente ser ouvido pelo professor pode contribuir para tornar a matemática menos mágica e mais humana, mais próxima dos alunos.

\section{REFERÊNCIAS}

ARAÚJO, N. S. R. A Educação de Jovens e Adultos e a resolução de problemas matemáticos. Dissertação (Mestrado em Educação para a Ciência e a Matemática) Universidade Estadual de Maringá, Maringá 2007.

BACQUET, M. Matemática sem dificuldades: ou como evitar que seja odiada por seu 
aluno. Tradução de: SCHNEIDER, M. E. Porto Alegre: Artmed, 2001.

BELLINI, M.; RUIZ, A. Matemática: epistemologia genética e escola. Londrina: EDUEL, 1998.

BRÄKLING, K. Escrita e produção de texto na escola. Disponível em: <http:// www.educare.org.br.educa/oassunto/index.cfm?pagina $=$ interna\&id_tema $=9 \&$ id subtema $=3 \& c d$ area_atv $=2>$. Acesso em: 26/11/2006.

D'ANTONIO, S. R. Linguagem e matemática: uma relação conflituosa no ensino? Dissertação (Mestrado em Educação para a Ciência e a Matemática) - Universidade Estadual de Maringá, Maringá 2006.

DOMADHY-DAMI, C.; BANKS-LEITE, L. As provas operatórias no exame das funções cognitivas. In: LEITE, L. B.; MEDEIROS, A. A. (Orgs.). Piaget e a Escola de Genebra. São Paulo: Cortez, 1987. p. 111-123.

FERREIRA, M. C. L. Da ambigüidade ao equívoco: as resistências da língua nos limites da sintaxe e do discurso. Porto Alegre: EDUFRGS, 2000.

GÓMEZ-GRANELL, C. Rumo à epistemologia do conhecimento escolar: o caso da educação matemática. In: RODRIGO, M. J.; ARNAY, J. (Orgs.). Domínio do conhecimento, prática educativa e formação de professores: a construção do conhecimento escolar. Tradução de: SCHILLING, C. São Paulo: Ática, 1998. v. 2. p. $15-41$.

HENRY, P. A. A ferramenta imperfeita: língua, sujeito e discurso. Tradução de: CASTRO, M. F. P. de. Campinas: Editora da UNICAMP, 1992.

KLEIMAN, A. Texto e leitor: aspectos cognitivos da leitura. 9. ed. Campinas: Pontes, 2004.

KLÜSINER, R. Ler, escrever e compreender a matemática, ao invés de tropeçar nos símbolos. In: NEVES, I.; SOUZA, J.; SCHAFFER, N. O.; GUEDES, P.; KLÜSINER, R. (Orgs.) Ler e escrever: compromisso de todas as áreas. Porto Alegre: EDURGS, 2000. p. 175-189.

LOPES, S. E. Alunos do ensino fundamental e problemas escolares: leitura e interpretação de enunciados e procedimentos de resolução. Dissertação (Mestrado em Educação para a Ciência e a Matemática) - Universidade Estadual de Maringá, Maringá, 2007.

MACHADO, N. J. Matemática e língua materna: análise de uma impregnação mútua. 5. ed. São Paulo: Moderna, 1995.

MEDEIROS, C. F. de. Modelos mentais e metáforas na resolução de problemas 
matemáticos verbais. Ciência e Educação, Bauru, v. 7, n. 2, p. 209-234, 2001.

PEDRO, E. $O$ discurso na aula: uma análise sociolingüística da prática escolar em Portugal. Lisboa: Edições Rolim, 1992.

SANTORUM, K. Ensinar a ler: como fazer? Disponível em: <http://www.unisc.br/ cursos/pos_graduaçao/mestrado/letras/anais_2coloquio/ensinar_a_ler.pdf $>$. Acesso em: 26/1/2007.

SMITH, F. Compreendendo a leitura. Uma análise psicolingüística da leitura e do aprender a ler. Tradução de: SCHILLING, Cláudia. Porto Alegre; Artes Médicas, 1989.

SOLÉ, I. Estratégias de leitura. Tradução de: SCHILLING, Cláudia. Porto Alegre: Artmed, 1998. 